\title{
Seismic behaviour: over-resistance effects on buildings
}

\author{
J. A. Avila \\ Institute of Engineering, National University of Mexico, Mexico and \\ Faculty of Engineering, National University of Mexico, Mexico
}

\begin{abstract}
The damage levels observed in the field, due to the 1985 earthquakes, is compared in a building in Mexico City with the analytical predicted behavior with, and without, the available over-resistance effects. The results were compared to those obtained from the conventional seismic analysis and to the observed damage behavior after the earthquake. Even the structures behaviour, located in soft soil in Mexico City, are qualified as adequate; there were some problems in some buildings, especially those between 7 to 17 levels. The structures behavior shows that these count with a certain over-resistance range that has been indirectly included and that was possibly the reason that a great number of buildings have not collapsed, even though they suffered severe damage. Elastic and inelastic time-history analyses are made. The soil-structure interaction and the P- $\Delta$ effects are included in the analysis. The analytical periods are compared to those experimentally obtained. A very good congruency between the analytically predicted behavior and the observed damage level after the earthquake is obtained. The direction and the stories with maximum damage match with the direction and stories with maximum deformations obtained from the analysis. The structural element resistances determined in a nominal way result were quite low compared to their real average values. It is noticed that the structure has a superior lateral resistance capacity compared to that given in the conventional design.
\end{abstract}

\section{Introduction}

Even the behavior of structures located in the soft zone in Mexico City, and subject to the 1985 earthquakes, are qualified as satisfactory; there were some 
problems in some of them, especially in the 7 to 17 levels of buildings. The structural behavior shows that these structures fall within a certain overresistance range that has been given and that it was possibly the reason that a great number of buildings have not collapsed, even though they showed severe damage. Considering the observed behavior in many buildings, the necessity of studying in detail the available over-resistance effects was merged in order to widely explain the seismic-resistance behavior participation of such structures. The inelastic response of a structure that suffered damage in the 1985 earthquake was analyzed in this work prior to the SCT-EW record of the 19th September 1985 earthquake. The results were compared to those obtained from the conventional seismic analysis and to the damage behavior observed after the earthquake.

\section{Elastic response}

\subsection{Building description}

The earthquake resistant system was based on frames in the longitudinal direction. The short direction head axis had four shear walls, and the internal axis had only frames (see fig. 1). The foundation was semi-compensated with a 6.425 meters deep rigid box, a foundation beam grid and friction piles of 22 meters in length. The building was constructed between 1970 and 1971. During the project, the structure was considered type A (important).

\subsection{Damage description}

There was only longitudinal direction damage between the ground level and level 6. The evidence of plastic hinges in the frame beam extremes in this direction was evident. Plastic hinges were observed in the base of the columns located in the ground level as well as diagonal fissures in some 3-4 and 5-6 stories columns.

\subsection{Over-resistance effects}

The over-resistance sources studied were: 1) slab steel (additional to the beam); 2) hardening effect because of the reinforcement steel strain (EPD); 3) average real stress in steel and concrete; 4) slab participation in the beam positive flexural moment resistance; 5) concrete core confinement. Table 1 shows the flexural moment resistances calculated values of a beam type, with and without over-resistances. In order to appreciate the differences between values, case 1 was taken as a base; fig. 2 shows the flexural moment-curvature curves for each one of the considered cases. The given confinement by the transversal reinforcement steel does not practically produce any section resistance increase; nevertheless, a confined section is capable of resisting a much bigger deformation than one without the confinement. Notice that the deformation capacity is independent of the steel stress-strain model, or if the slab participation is considered or not. The hardening zone consideration by reinforcement steel strain, was one of the most important; the results in a 
resistance level show significant increase, according to case 1. This type of comparison is also made in columns with flexural moment-axial force interaction diagrams; the differences obtained presented a similar pattern found in beams.
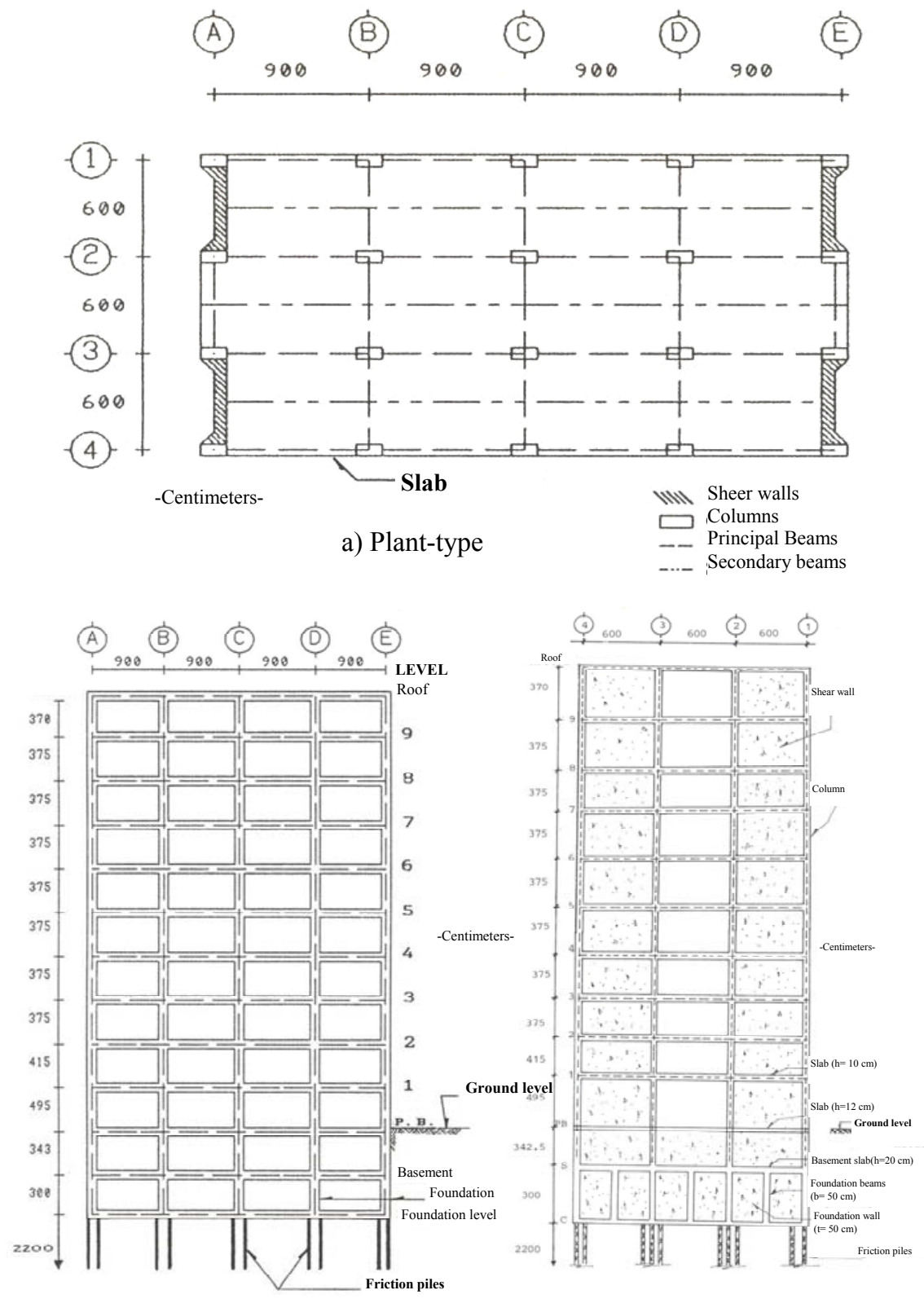

Figure 1: $\quad$ Structural plant-type and cuts (dimensions in meters). 
16 Earthquake Resistant Engineering Structures VI

Table 1: $\quad$ Flexural moment resistances calculated values of a beam type, with and without over-resistances.

\begin{tabular}{|l|c|c|c|c|}
\cline { 2 - 5 } \multicolumn{1}{c|}{} & 1 & 2 & 3 & 4 \\
\hline MR+(t-m) & 83.95 & 84.09 & 109.32 & 109.98 \\
\hline MR- (t-m) & 146.40 & 147.51 & 152.83 & 156.18 \\
\hline
\end{tabular}

\begin{tabular}{|l|c|c|c|c|}
\cline { 2 - 5 } \multicolumn{1}{c|}{} & 5 & 6 & 7 & 8 \\
\hline MR+ (t-m) & 84.15 & 84.26 & 111.94 & 112.17 \\
\hline MR- (t-m) & 177.09 & 178.75 & 174.09 & 178.96 \\
\hline
\end{tabular}

\begin{tabular}{|l|c|c|c|c|}
\cline { 2 - 5 } \multicolumn{1}{c|}{} & \multicolumn{1}{c|}{9} & 10 & 11 & 12 \\
\hline MR+ (t-m) & 89.83 & 123.20 & 101.68 & 132.12 \\
\hline MR- (t-m) & 177.09 & 178.96 & 209.51 & 213.15 \\
\hline
\end{tabular}

\begin{tabular}{|c|c|}
\hline CASE & \multicolumn{1}{|c|}{ CONSIDERATIONS } \\
\hline 1 & Rectangular beam, without slab reinforcement; S/C; EPP; E/N \\
\hline 2 & Rectangular beam, without slab reinforcement; C/C; EPP; E/N \\
\hline 3 & Rectangular beam, without slab reinforcement; S/C; EPD; E/N \\
\hline 4 & Rectangular beam, without slab reinforcement; C/C; EPD; E/N \\
\hline 5 & Rectangular beam, with slab reinforcement; S/C; EPP; E/N \\
\hline 6 & Rectangular beam, with slab reinforcement; C/C; EPP; E/N \\
\hline 7 & Rectangular beam, with slab reinforcement; S/C; EPD; E/N \\
\hline 8 & Rectangular beam, with slab reinforcement; C/C; EPD; E/N \\
\hline 9 & "T" beam, with slab reinforcement; C/C; EPP; E/N \\
\hline 10 & "T" beam, with slab reinforcement; C/C; EPD; E/N \\
\hline 11 & Rectangular beam, with slab reinforcement; C/C; EPP; E/P \\
\hline 12 & Rectangular beam, with slab reinforcement; C/C; EPD; E/P \\
\hline
\end{tabular}

S/C - Without confinement

EPP - Perfectly elastic-plastic

$\mathrm{E} / \mathrm{N}$ - Nominal stresses
C/C - With confinement

EPD - Elastic-plastic with hardening

$\mathrm{E} / \mathrm{P}$ - Average real stresses 


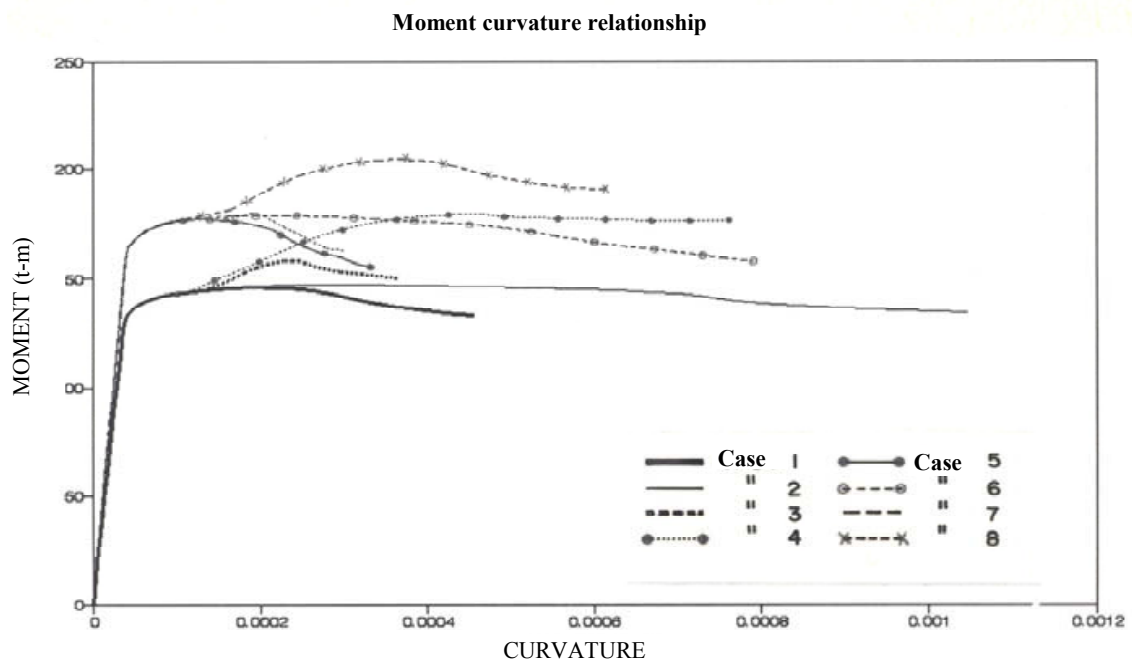

Figure 2: $\quad$ Moment curvature relationships of a beam type.

\subsection{Vibration periods}

The longitudinal direction vibration periods for the fixed base condition in ground level (PB) and in slab foundation level are practically the same, 1.67 and 1.69 seconds, respectively; when including the influence of the soil-structure interaction effects an increase of little more than the $10 \%$ was obtained, getting to 1.84 seconds (see table 2 ). The measured period (2.1 seconds) shows a great flexibility. The difference between can be attributed to the damage suffered in this direction for the lateral stiffness lost, regarding the maximum damage direction. The transversal direction vibration periods variation for the two fixed base types are practically nil, with 1.00 second for both conditions. Nevertheless, the period difference between the fixed base condition and the condition in which the soil-structure interaction effects were taken, gives significant results because of the increase of $30 \%$. Comparing this last and the measured result, they are nearly the same which is congruent so that this direction does not present damage.

\section{Inelastic responses}

\subsection{Studied cases}

The selected cases characteristics, from a total of 21 inelastic step-by-step analyzed cases, were: A (without confinement, EPB model, rectangular beam, $\mathrm{V} 3 \%, \mathrm{C} 1.5 \%$ ); B (without confinement, Takeda model, rectangular beam, V3\%, $\mathrm{C} 1.5 \%$ ); $\mathrm{C}$ (with confinement, Takeda model, rectangular beam, V3\%, C1.5\%); $\mathrm{D}$ (with confinement, EPB model, rectangular beam, V3\%, C1.5\%); E (with confinement, Takeda model, "T" beam, V3\%, C1.5\%); F (with confinement, 
EPB model, "T" beam, V3\%, C1.5\%); G (with confinement, EPB model, rectangular beam, $\mathrm{V} 3 \%, \mathrm{C} 1.5 \%, \mathrm{EP}) ; \mathrm{H}$ (with confinement, Takeda model, rectangular beam, $\mathrm{V} 3 \%, \mathrm{C} 1.5 \%, \mathrm{EP}) . \mathrm{EPB}$ : elastic-plastic bilinear hysteretic model, $\mathrm{V} 3 \%$ and $\mathrm{C} 1.5 \%$ : $3 \%$ and $1.5 \%$ slopes given to the program to take notice the deformation hardening effect in beams and columns, respectively, and EP: reinforcement steel and concrete average real stresses.

Table 2: $\quad$ Vibration periods of longitudinal and transversal directions.

\begin{tabular}{|l|l|l|l|}
\cline { 2 - 4 } \multicolumn{1}{c|}{} & \multicolumn{3}{c|}{ Base condition } \\
\hline Mode & $\begin{array}{l}\text { Fixed in } \\
\text { ground level }\end{array}$ & $\begin{array}{l}\text { Fixed in } \\
\text { foundation level }\end{array}$ & $\begin{array}{l}\text { Soil-structure } \\
\text { interaction }\end{array}$ \\
\hline 1 & 1.67 & 1.69 & 1.84 \\
\hline 2 & 0.55 & 0.56 & 0.63 \\
\hline 3 & 0.33 & 0.33 & 0.42 \\
\hline
\end{tabular}

Note: $\mathrm{T} 1$ (measured period) $=2.1$ seconds.

a) Longitudinal direction

\begin{tabular}{|l|l|l|l|}
\cline { 2 - 4 } \multicolumn{1}{c|}{} & \multicolumn{3}{c|}{ Base condition } \\
\hline 1 & $\begin{array}{l}\text { Fixed in } \\
\text { ground level }\end{array}$ & $\begin{array}{l}\text { Fixed in } \\
\text { foundation level }\end{array}$ & $\begin{array}{l}\text { Soil-structure } \\
\text { interaction }\end{array}$ \\
\hline 2 & 1.00 & 1.01 & 1.31 \\
\hline 3 & 0.27 & 0.27 & 0.51 \\
\hline
\end{tabular}

Note: $\mathrm{T} 1$ (measured period) $=1.3$ seconds.

b) Transversal direction

\subsection{Maximum horizontal displacements}

Using the Takeda hysteretic model (B, C, E and $\mathrm{H}$ cases) the lateral displacements result are bigger. The inelastic response is greatly diminished according to the elastic one; in fig. 3, A case with roof lateral displacement histories in longitudinal direction are compared, with inelastic and elastic behavior, respectively. The inelastic displacements tended to reduce a little more of $50 \%$ in the maximum accelerations range. The displacement histories amplitudes and behavior pattern for the other cases gives result very similar to A case. Fig. 4 compares the roof lateral displacement histories of the longitudinal direction (important damage frames) and transversal (no-damage concrete walls and frames) of the building in order to show the seismic-resistance behavior differences in both directions. The response in the short direction is quite smaller, which indicates the great available lateral stiffness by the shear walls presence in the head axis. During the analysis in this direction there were no yields detected. 


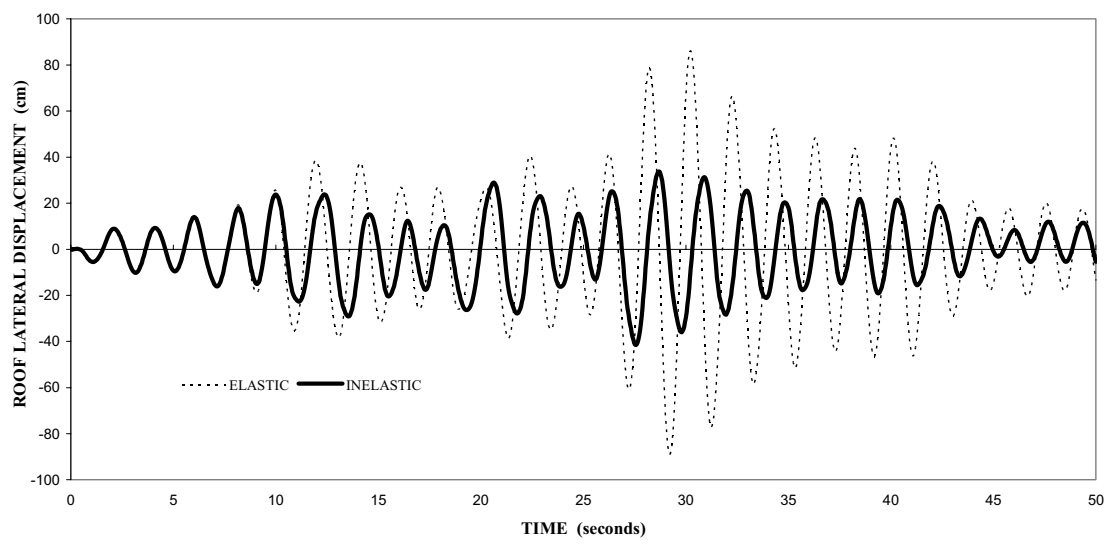

Figure 3: Roof lateral displacement histories in longitudinal direction, A case, inelastic and elastic behaviour.

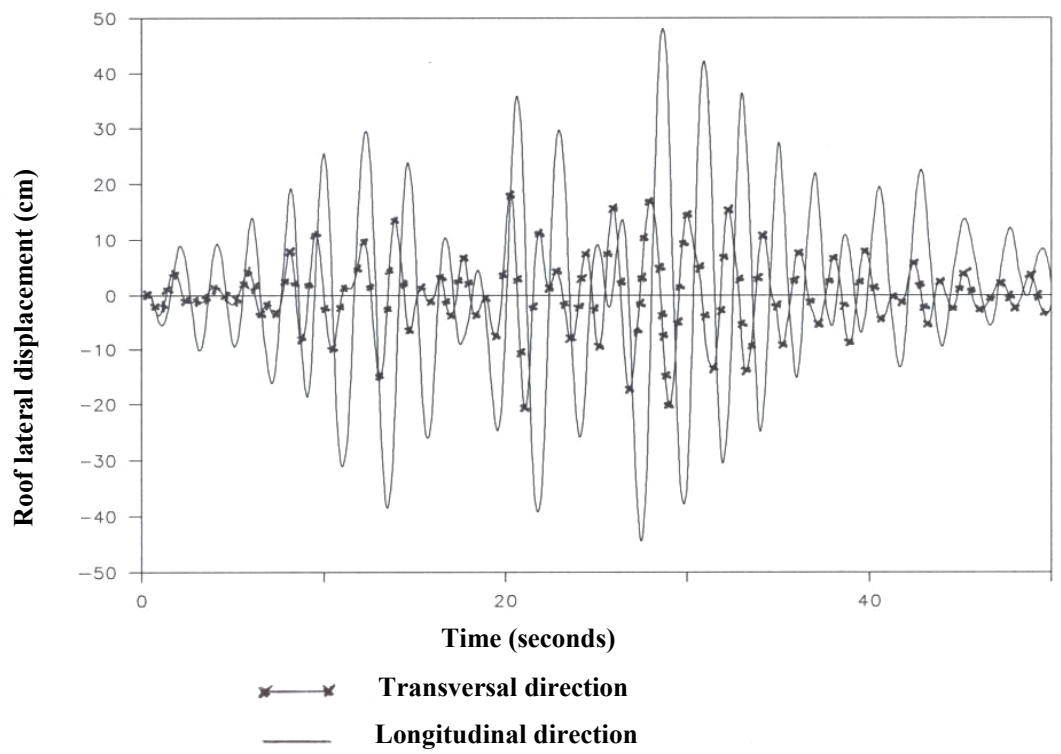

Figure 4: Roof lateral displacement histories of the longitudinal direction (important damage frames) and transversal (no-damage). 


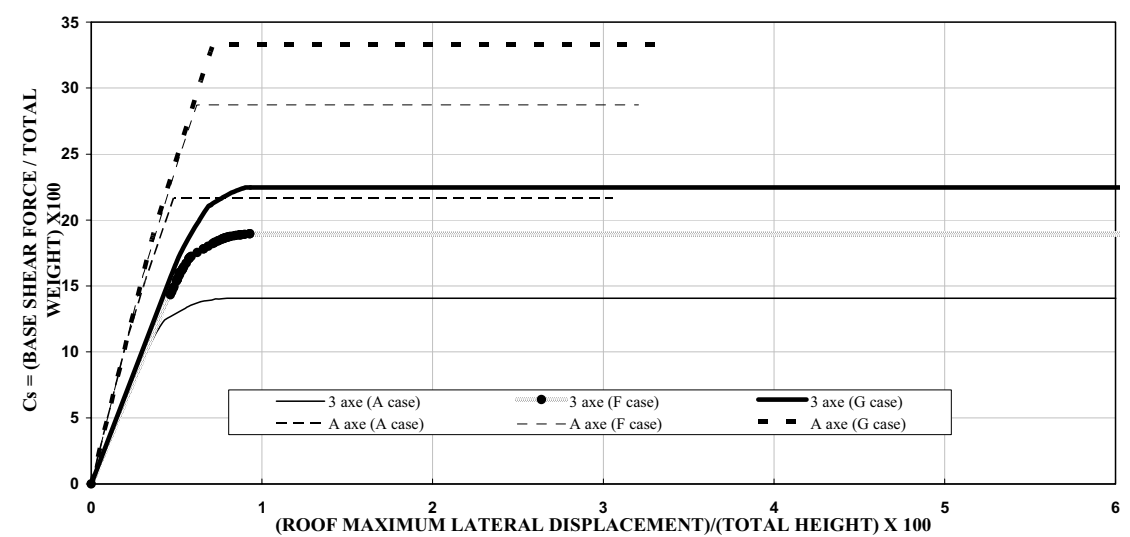

Figure 5: Base shear force-roof lateral displacement relations, non-linear static analysis, axes A-E (transversal direction), 3 axe (longitudinal direction) and, A, F and $\mathrm{G}$ cases.

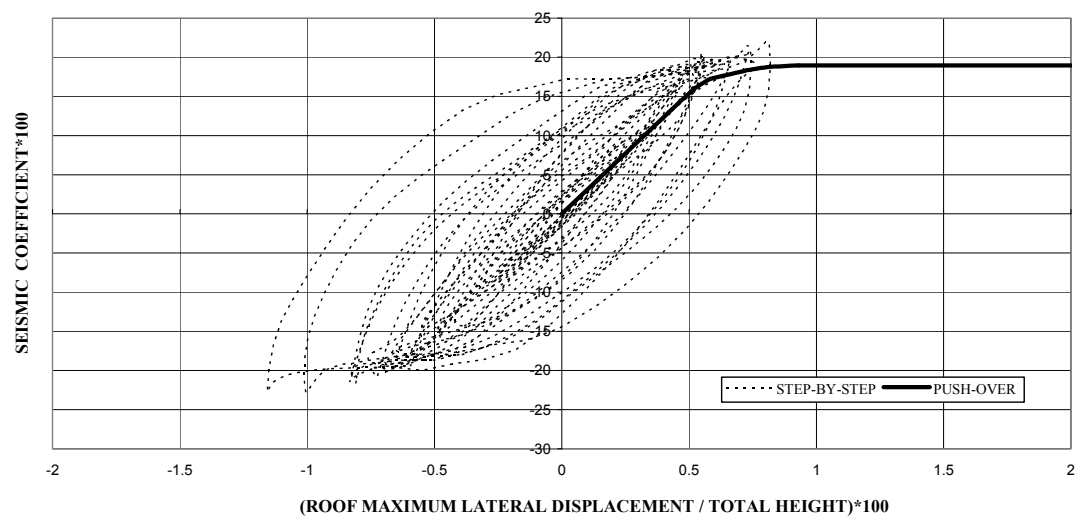

Figure 6: Base shear force-roof lateral displacement relations, $G$ case, inelastic step-by-step and static (Pushover) analysis, longitudinal direction

\subsection{Base shear force-roof lateral displacement relations}

In this study non-linear static analysis were made taking the structure in both directions, up to its collapsed condition, for a determined failure mechanism (see fig. 5). The results correspond to 3 axis (longitudinal direction), and to the axis A-E (transversal direction), for comparative purposes. The seismic loads distribution type was the result of a spectral modal dynamic analysis previously 
made. The employed resistances in the analysis were those obtained in A, F and $\mathrm{G}$ cases; the gravitational load effects were included in the responses. For the longitudinal direction, seismic coefficients of $0.14,0.19$ and 0.23 were obtained, for $A, F$ and $G$ cases respectively. In the step-by-step inelastic analysis, the results were $0.15,0.22$ and 0.25 . Regarding the transversal direction results under lateral load monotonically increase, the over-resistance effects employed were clearly shown, from 0.22 for the nominal case, it was an increase of 0.29 for the case in which the confinement, the slab participation for positive bending moment and nominal stress were considered, and reached 0.3 for the last case in which the confinement was used, rectangular beams an average stresses. In fig. 6 the base shear force-roof lateral displacement relations for the $G$ case are compared, obtained from the inelastic dynamic (step-by-step) and static (Pushover) analysis, longitudinal direction. In the horizontal axis we have the roof displacements divided between the building total height and in the vertical axis the seismic coefficients are presented, both responses in a percentage. In the inelastic static analysis the structure lateral resistance is lightly underestimated, because the second slope effect was not considered; nevertheless these results give a very good idea of such property. Including the $\mathrm{G}$ case over-resistances, the inelastic excursion cycle numbers diminishes in an important way and the seismic coefficient increases to $50 \%$, according to the A case results. The differences between the two analysis types are due mainly to the hypothesis in which every one of the employed computer programs is supported.

\subsection{Local ductility maximum demands in beams and columns}

Fig. 7 shows the observed damage distribution, as well as the global distribution of the plastic hinges in $\mathrm{A}, \mathrm{E}$ and $\mathrm{H}$ cases. The results for $\mathrm{E}$ case present bigger similitude to the physically observed case; A case is presented for being the case in which the conventional criteria for the resistance calculation is supported. $\mathrm{H}$ case resulted very similar to E case. For the three cases, A, E and H, the local ductility maximum demands " $\mu_{\mathrm{L}}$ " were also calculated by level, for beams and columns. The developed maximum demands in beams were concentrated in the first level, and in the inferior extremes in columns of ground level; in columns the values that result are small and not very important. The structural element resistances determined in a nominal way resulted in their being quite lower than their average real values.

\section{Conclusions}

In general there was a good congruency between the calculated behavior and the observed damage level after the earthquake. The vibration periods showed that the structure presented a great flexibility in one of its directions. The direction and the stories with maximum damage match with the direction and stories with maximum deformations obtained from the analysis. It is noticed that the structures have a superior lateral resistance capacity regarding to those given in the conventional design; calculating the inelastic seismic responses with the 
nominal resistances could get us to a greatly overestimated non-linear behavior value, global and locally. The mechanism that tends to be formed in each case, independently of the resistance type, matches with the design philosophy "weak beam-strong column", the most part of plastic hinges are formed in the beam extremes.

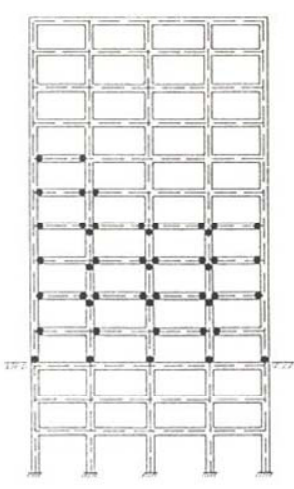

a) Observed damages distribution

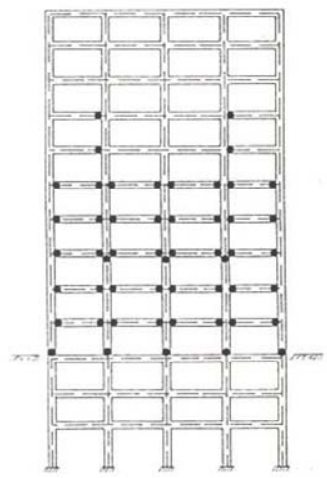

c) E case

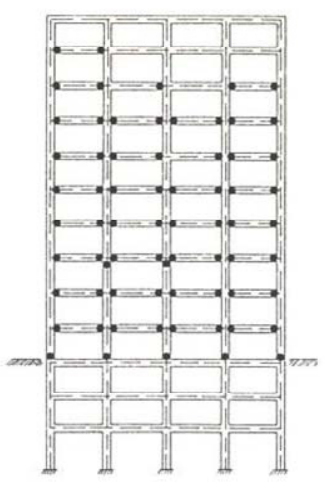

b) A case

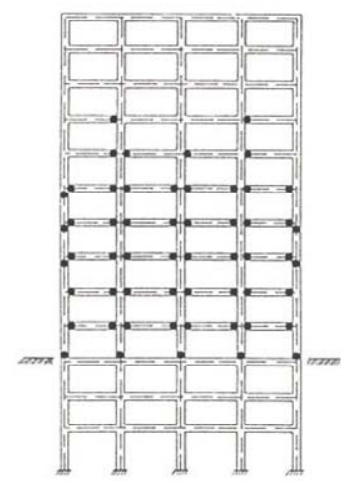

d) $\mathrm{H}$ case

Figure 7: Observed damage distribution and global distribution of the plastic hinges in $\mathrm{A}, \mathrm{E}$ and $\mathrm{H}$ cases. 